\title{
COSTING DRUG DEVELOPMENT
}

\author{
Where did that number come from? The eagerly awaited publication of the full study from DiMasi \\ and colleagues invites us to analyse the cost of bringing new drugs to market.
}

$\$ 802$ million. Although first introduced in 2001, it is already a very familiar figure. This latest estimate from the Tufts Center for Drug Development of the cost of developing a new chemical entity to the point of submission for regulatory approval has already been widely debated. Well, now you can judge for yourself, as the full paper describing the methodology used to derive this number is published this month in the Journal of Health Economics ${ }^{1}$.

The team of Joseph DiMasi, Ronald Hansen and Henry Grabowski are the recognized leaders in this field. Others have also estimated the costs of drug discovery and development, such as the Boston Consulting Group's 2001 figure of US $\$ 880$ million, but nobody else bases their estimates on such a wealth of project-level data and openly publishes their methodology. The team's previous analysis in 1991 gave us the figure of US \$231 million (in 1987 dollars), which became the benchmark figure for the industry throughout the 1990s. We can expect to live with US $\$ 802$ million for years to come.

So, what are the numbers based on? DiMasi and colleagues randomly selected 68 new drugs in development that were first tested in humans anywhere in the world between 1983 and 1994. Within this sample there were 61 small-molecule drugs, four recombinant proteins, two monoclonal antibodies and one vaccine. These drugs derived from ten multinational pharmaceutical companies that were confidentially surveyed to obtain their estimated R\&D costs for each of these new products. The drug pipeline was divided into four phases: a preclinical phase that encompasses both discovery and preclinical testing, and three stages of clinical development in humans. Using estimated failure rates at each stage, DiMasi and colleagues allocated the costs of unsuccessful projects to those that resulted in marketed new products.

Their analysis yields an 'out-of-pocket' cost of US $\$ 403$

"We can expect to live with US $\$ 802$ million for years to come." costs up to the point of marketing approval. Their cost-ofcapital estimate for the period covered (up to 2000) was $11 \%$, which gives a capitalized cost per successful new drug of US $\$ 802$ million, with US $\$ 467$ million of that applying to the clinical period. So $50 \%$ of the total cost of drug development is attributed to what the authors describe as 'time costs'. Although second nature to economists, the addition of these time costs might come as a surprise to the rest of us. For instance, knowing that you have some expensive but hardly worn piece of clothing from years back hanging in the wardrobe is distressing enough, without thinking about the cost-of-capital invested in it.

Other interesting numbers lurk within the paper. The authors have also made an estimate of post-approval R\&D costs, giving a figure for the entire development and marketing life-cycle of US \$897 million (US \$543 million pre-capitalization). As the average approval date for the compounds sampled was 1997, figures for compounds approved after that date would be expected to be higher, and the pre-approval costs for a drug approved in 2001 are estimated at US $\$ 1.1$ billion (US $\$ 540$ million precapitalization). For R\&D cycles initiated in 2001, and resulting in a drug approved in 2013, the costs might be US $\$ 1.9$ billion (US $\$ 970$ million pre-capitalization).

Since its appearance in 2001, the figure of US $\$ 802$ million has often been incorrectly described as the "price of drug development." In fact, it is the estimated cost of bringing a new drug to the end of Phase III clinical testing. The majority of pharmaceutical products receiving marketing approval each year are of course not new drugs, but line extensions of existing ones. The development costs of line extensions are much lower than those for new drugs, so averaging out the costs of all drugs will necessarily yield a much lower cost per marketed product. Nevertheless, although the doubling of costs due to capitalization might cause some raised eyebrows, one can also argue that in the face of so many unmet medical needs, drug development is cheap at twice the price.

1. DiMasi, J. A., Hansen, R. W. \& Grabowski, H. G. The price of innovation: new estimates of drug development costs. J. Health Econ. 835, 1-35 (2003). 